\title{
TRANSITIONING OF FINAL YEAR NURSING STUDENTS TO PROFESSIONAL NURSES: A BEST PRACTICE GUIDELINE
}

\section{D. van Rooyen*}

Faculty of Health Sciences

e-mail: dalena.vanrooyen@nmmu.ac.za

\section{P. Jordan*}

Department of Nursing Science

e-mail: portia.jordan@nmmu.ac.za

\section{E. M. Caka}

South African Military Health Service

Bloemfontein, South Africa

e-mail: caka@polka.co.za

\section{W. ten Ham-Baloyi*}

Faculty of Health Sciences

e-mail: wilma.tenham-baloyi@nmmu.ac.za

${ }^{*}$ Nelson Mandela Metropolitan University

Port Elizabeth, South Africa

\section{ABSTRACT}

The period of transition from student nurse to professional nurse in various healthcare contexts can be challenging. No best practice guideline could be found that served to optimize the transition of final year nursing students to professional nurses in the South African Military Health Service (SAMHS). A draft guideline was developed, based on data from interviews with students and professional nurses and from an integrative literature review including guidelines on the transition of final year nursing students to professional nurses to formulate content. Format was guided by using the AGREEII instrument. The draft guideline was piloted using six expert reviewers. The guideline provides direction to the following: provide support, foster socialization and belonging, enhance a positive clinical learning environment and ensure retention of newly qualified professional nurses. The guideline can potentially be used by nurse educators and managers in the SAMHS but requires implementation to determine its impact on a successful transition period from student to professional nurse.

Keywords: best practice guideline, education, final year nursing student, military health service, professional nurse, transition 


\section{INTRODUCTION}

Transition of final year nursing students to professional nurses is viewed as a period of education and alteration to what is needed in the nursing profession in which the graduated student obtains skills, knowledge and ethical standards to take up the role of becoming an competent member in the nursing team (Hayman-White et al. 2007, 189). The transition period may constitute three phases, namely: the separation phase, transition phase and incorporation phase. The separation phase is characterized by parting from being a student to being a mature clinical practitioner; the transition phase reflects the movement into the new roles and responsibilities of the novice nurse; and incorporation phase relates to assimilation into the field of experts with knowledge and skills (Wielandt et al. 2007, 317).

If effective transition does not occur, newly qualified nurses will feel incompetently equipped for the daily tasks and the role of a professional nurse as well as feeling unfit and incompetent for practice, leading to a high attrition rate (Hayman-White et al. 2007, 190; Mooney 2007, 1615). Spoelstra and Robbins $(2010,11)$ suggest that transition should be initiated within the six months prior to qualification as a professional nurse, as this will foster a foundation for awareness and expectation of the roles novice nurses are expected to fulfil.

Furthermore, to facilitate role transition, a learning environment should be in place that supports critical thinking and amalgamation of information with a learner-centred approach (Spoelstra and Robbins 2010, 13). Mooney (2007, 1616) concurs, stating that the clinical learning area should be a powerful catalyst that influences students' learning and should prepare them for the transition to becoming professional nurses. As part of a conducive learning environment, the new graduate needs time and transition resources to meet the expectations of their new role as a professional nurse (Goodwin-Esola, Deely and Powell 2009, 412). Importantly, facilitating a smooth transition is the joint responsibility of the educational institutions, the healthcare institutions as well as the professional nurses in these institutions as they prepare the final year nursing students for their role of being competent professional nurses (Hayes 2014; Hollywood 2011, 665; Mannix, Wilkes and Luck 2009, 63).

Few guidelines have been developed globally in order to facilitate the transition of final year nursing students into professional nurses. The guidelines that are available recommend that several factors facilitate the smooth transition of graduate to professional nurse. These include a supportive and positive organisational culture that values learning as well as their staff: provision of resources to implement the graduate transition (such as preceptors and mentors); and a transition program as well as collaborative relationships between educational institutions (Department of Health and Human Services 2015; Hayes 2014; Healy and Howe 2012; Klomp 2009; Rush, Adamack and Gordon 2013). 
The transition period for nursing students in the South African Military Health Service (SAMHS). is especially challenging as they have to be military trained to ensure combat readiness as well as adhere to nursing practice demands to take up their new role of being a nursing officer. For example, before commencement of the four-year nursing training to become professional nurses, students undergo military training for six months (termed "officer's forming course") and are supposed to implement this training throughout the four years as soldiers and nurses. Thus, adjusting to these two environments - military service and health care - and the dichotomy in their distinct roles is what signifies the military nurse's transition as unique.

Furthermore, the hierarchical structure in the military, where the military rank is recognized above the professional qualification as a nurse, provides challenges during the period of transition. The uniqueness of the military context therefore requires specially designed guidelines to best manage this unique transition for students. However, no published best practice guideline could be found internationally for the transition of final year nursing students to professional nurses in the military health context. According to the third author of this article, who is employed by the SAMHS, the SAMHS has no evidence-based policies, procedures nor guidelines in place on transition, indicating the need for a best practice guideline in this context. This study therefore was conducted to develop and review a best practice guideline facilitating the transition of final year nursing students to professional nurses in the SAMHS. This article addresses the development and review of a best practice guideline facilitating the transition of final year nursing students to professional nurses in the SAMHS, which was the final phase (Phase 3) of a doctoral study.

\section{METHOD}

A three-phased approach was used to develop a best practice guideline for the transition of final year nursing students to professional nurses in the military health service in South Africa (Caka 2015). The entire study was conducted by the third author and supervised by the first and second authors. Phase 3 was conducted in 2014 (April - November). Prior to the study, ethical clearance was obtained from the Ethical Board at the XXX University (ethics number H14HEA-NUR-014) as well as from the Defense Intelligence, Department of Defense (ethics number $3 \mathrm{MH} / \mathrm{R} / 84003086 \mathrm{MC}$ ). Consent was obtained from the participants that served as experts in order to review the guideline.

A summary of the phases of the study are outlined in Figure 1. Details of Phases 1 and 2 are documented elsewhere (Caka, Van Rooyen and Jordan 2015, 191; Van Rooyen et al. 2018, 36-39). Phase 3 is discussed in this article. 


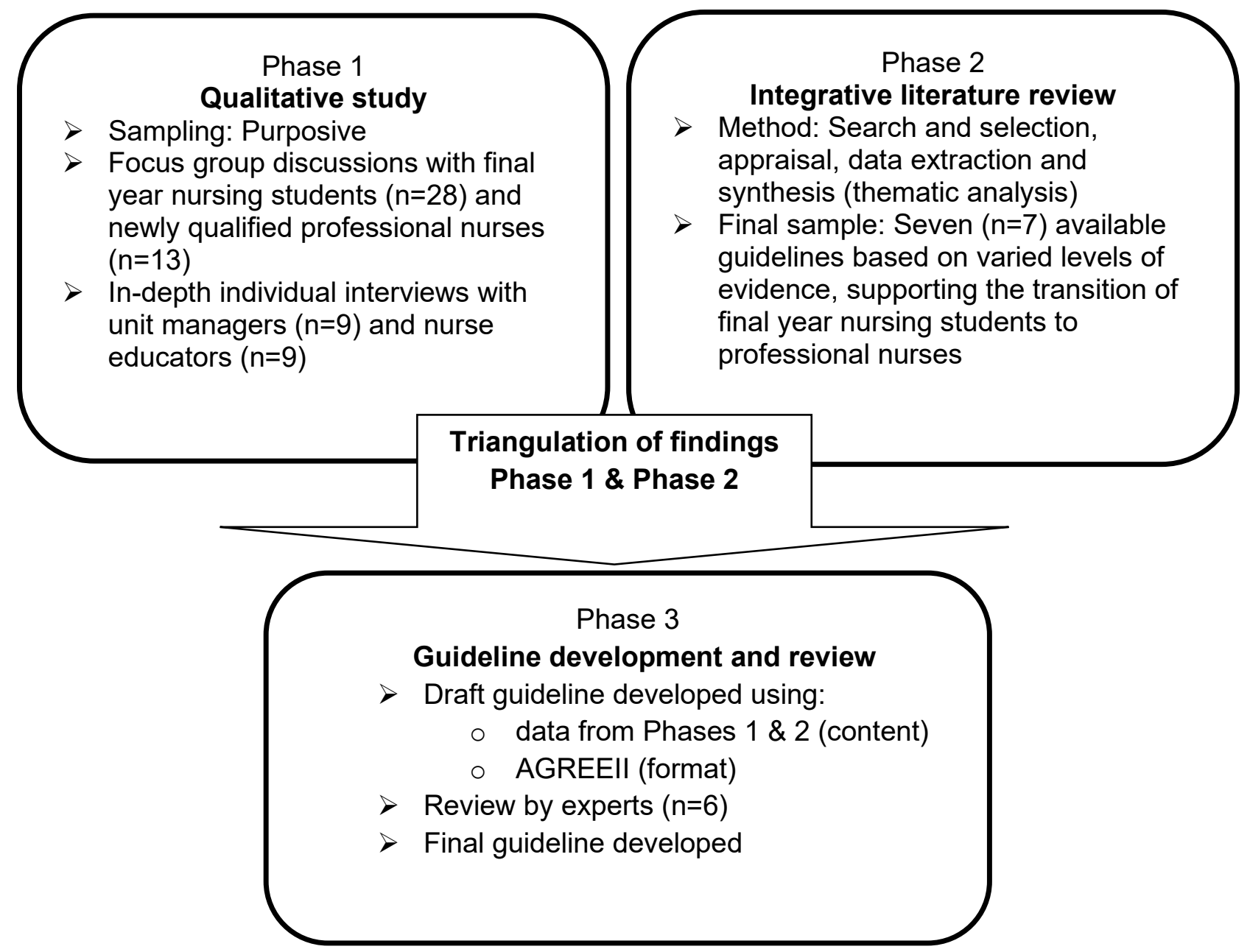

Figure 1: Phases and methods

\section{Development of the best practice guideline}

Triangulation of the findings of Phases 1 and 2 resulted in confirmation of four directives, namely: (1) provide support for final year nursing students and newly qualified professional nurses; (2) foster professional socialization and belonging; (3) enhance a positive clinical learning environment; and (4) ensure retention of newly qualified professional nurses. These directives formed the basis of the content of the developed draft guideline. For the format of the draft guideline, the AGREEII tool was used (Brouwers 2013). The draft guideline was assessed by the first two authors, both experts in guideline development.

\section{Review of the best practice guideline}

Expert reviewers, comprising of six $(n=6)$ participants, were purposively selected by the third author, based on them having expertise in nurse education and training, guideline review or 
nursing management in the training or clinical areas in SAMHS. The reviewers included three participants (Reviewers 1, 2 and 3) who are academics and educators at different South African universities and who are experienced in the review of guidelines, one participant (Reviewer 4) who is a nurse educator and manager employed as the head of the military nursing college, one participant (Reviewer 5) in the nursing directorate at a facility of SAMHS and one participant (Reviewer 6) who is a quality insurance manager for the SAMHS. Reviewers 4, 5 and 6 have specific responsibility to ensure successful transition of final year nursing students due to the contexts in which they are employed.

Nursing students were not included as part of the expert reviewers as the guideline is developed to be used by nurse educators and nurse managers. However, the results of focus group discussions conducted with 28 final year nursing students in Phase 1 of the study contributed towards development of the guideline (see Figure 1).

In order for the expert reviewers to assess the draft guideline, the researcher used the 23 items of the AGREEII appraisal instrument (Brouwers 2013). These 23 items are organised within six domains, where each domain captures a specific aspect of guideline quality (see Table 1).

Due to logistical constrains, as reviewers were situated in several provinces of the country, email was used as a mean to obtain their consent to participate in the study and, subsequently, their feedback on the guideline. Prior to data collection, the selected expert reviewers were sent an electronic consent form. All six members agreed to participate. Thereafter the members were sent the draft guideline with the AGREEII tool and given instructions to complete the AGREEII and to make comments, suggestions and/or recommendations as required for the first round. A period of two weeks was granted for the reviewers to give feedback.

Table 1: Domains and items of the AGREEIl appraisal instrument (Brouwers 2013)

\begin{tabular}{|c|c|}
\hline Domain & Items \\
\hline $\begin{array}{l}\text { Domain 1: Scope and } \\
\text { Purpose }\end{array}$ & $\begin{array}{l}\text { 1. Overall objective(s) of the guideline is (are) specifically described } \\
\text { 2. Health question(s) covered by the guideline is (are) specifically described } \\
\text { 3. Population (patients, public, etc.) to whom the guideline is meant to apply is } \\
\text { specifically described }\end{array}$ \\
\hline $\begin{array}{l}\text { Domain 2: Stakeholder } \\
\text { Involvement }\end{array}$ & $\begin{array}{l}\text { 4. Guideline development group includes individuals from all relevant } \\
\text { professional groups } \\
\text { 5. Views and preferences of the target population (patients, public, etc.) have } \\
\text { been sought } \\
\text { 6. Target users of the guideline are clearly defined }\end{array}$ \\
\hline $\begin{array}{l}\text { Domain 3: Rigor of } \\
\text { Development }\end{array}$ & $\begin{array}{l}\text { 7. Systematic methods were used to search for evidence } \\
\text { 8. Criteria for selecting the evidence are clearly described } \\
\text { 9. Strengths and limitations of the body of evidence are clearly described } \\
\text { 10. Methods for formulating the recommendations are clearly described } \\
\text { 11. Health benefits, side effects, and risks have been considered in formulating } \\
\text { the recommendations } \\
\text { 12. There is an explicit link between the recommendations and the supporting } \\
\text { evidence }\end{array}$ \\
\hline
\end{tabular}




\begin{tabular}{|c|c|}
\hline Domain & Items \\
\hline & $\begin{array}{l}\text { 13. Guideline has been externally reviewed by experts prior to its publication } \\
\text { 14. Procedure for updating the guideline is provided }\end{array}$ \\
\hline $\begin{array}{l}\text { Domain 4: Clarity of } \\
\text { Presentation }\end{array}$ & $\begin{array}{l}\text { 15. Recommendations are specific and unambiguous } \\
\text { 16. Different options for management of the condition or health issue are clearly } \\
\text { presented } \\
\text { 17. Key recommendations are easily identifiable }\end{array}$ \\
\hline Domain 5: Applicability & $\begin{array}{l}\text { 18. Guideline describes facilitators and barriers to its application } \\
\text { 19. Guideline provides advice and/or tools on how the recommendations can } \\
\text { be put into practice } \\
\text { 20. Potential resource implications of applying the recommendations have been } \\
\text { considered } \\
\text { 21. Guideline presents monitoring and/or auditing criteria }\end{array}$ \\
\hline $\begin{array}{l}\text { Domain 6: Editorial } \\
\text { Independence }\end{array}$ & $\begin{array}{l}\text { 22. Views of the funding body have not influenced the content of the guideline } \\
\text { 23. Competing interests of guideline development group members have been } \\
\text { recorded and addressed }\end{array}$ \\
\hline
\end{tabular}

Each item was scored using the Likert scale of 1 (strongly disagree) to 7 (strongly agree). For one rating, the maximum possible overall score for the 23 items is as follows: 7 (strongly agree) $\mathrm{x} 23$ (items) $=161$. The minimum possible overall score for the 23 items is 1 (strongly disagree) x 23 (items) $=23$. The score per domain (in \%) was calculated as follows:

(Obtained score - minimum possible score $x$ number of reviewers) / (Maximum possible score $x$ number of reviewers - minimum possible score $x$ number of reviewers) $x 100$.

To calculate the overall score per reviewer, an adapted scoring system was used rather than calculating the overall score of all reviewers per domain as stipulated in the AGREEII's instructions. The overall score (in \%) per reviewer was calculated as follows:

Obtained score/Maximum possible score $x 100$.

The higher the overall score obtained, the greater was the consensus related to the items and domains assessed, thus validating the content of the clinical guideline. For this study an overall rate per reviewer of 70 per cent and above was accepted.

\section{RESULTS}

\section{Outcome of the review of the best practice guideline}

The overall score per domain was 61 per cent for Scope and Purpose (Domain 1), 75 per cent for Stakeholder Involvement (Domain 2), 74 per cent for Rigor of Development (Domain 3), 76 per cent for Clarity and Presentation (Domain 4), 55.5 per cent for Applicability (Domain 
5) and 65 per cent for Editorial Independence (Domain 6).

Recommendations and overall scores per reviewers were as follows. No recommendations or comments were made by reviewer 5, (who scored the guideline with an overall score of $83 \%$ ). The remaining 5 reviewers gave the following recommendations: health benefits and risks of the recommendations of the guideline must be clearly stated (Reviewers 1 (93\%) and 2 $(63 \%))$ as well as each user (Reviewer 2); more supporting evidence for the recommendations must be given (Reviewer $4(67 \%)$ ); piloting of the guideline should be mentioned as well as that permission was obtained from the Defense Intelligence and the cost implications of applying the guideline should be stated more clearly (Reviewer 2). Furthermore, a background could be given to address the need of the guideline and mention should be made on how the guideline could be implemented (Reviewer 3 (61\%)). Finally, the stakeholder involvement should clearly state that the group comprised of nurses only (Reviewer $6(70 \%)$ ).

Based on the feedback, the guideline was adapted. As there was some variability of the scores obtained per reviewer, which ranged between 61 per cent and 93 per cent, a second round of review was initiated in order to get consensus. The three reviewers $(n=3)$ that scored the overall guideline below 70 per cent (Reviewer 2, 3 and 4) were requested to review the guideline a second time. In the second round of review, a more consensual percentage (of $70 \%$ and above) was reached by all three reviewers, with an overall final score of 77.5 per cent, indicative of a more acceptable guideline. The scores in both round one and round two are depicted in Table 2.

Table 2. Scores from the expert reviewers for Round 1 and 2

\begin{tabular}{|l|c|c|c|}
\hline \multicolumn{1}{|c|}{ Reviewer } & $\begin{array}{c}\text { Score in \% } \\
\text { (Round 1) }\end{array}$ & $\begin{array}{c}\text { Score in \% } \\
\text { (Round 2) }\end{array}$ & Final score in \% \\
\hline Reviewer 1 - Academic & 93 & - & 93 \\
\hline Reviewer 2 - Academic & 63 & 75 & 75 \\
\hline Reviewer 3 - Academic & 61 & 73 & 73 \\
\hline Reviewer 4 - Head, military nursing college & 67 & 71 & 71 \\
\hline Reviewer 5 - Nursing directorate SAMHS & 83 & - & 83 \\
\hline Reviewer 6 - Quality insurance manager, SAMHS & 70 & - & 70 \\
\hline Overall final score & & & 77.5 \\
\hline
\end{tabular}

The shortened version of the final guideline based on the four themes from the triangulated data in Phase 1 and 2 are outlined below. The full version of the guideline is available from the first author. 


\section{THE GUIDELINE}

\section{Title: A best practice guideline facilitating the transition of final year nursing students to professional nurses in SAMHS}

Objective: To make recommendations for facilitating the transition process from student nurse to professional nurse in the SAMHS.

Target population: The guideline is intended for use by nurse educators and unit managers to facilitate the transition of final year nursing students and to better prepare the novice professional nurses to take up the role of being professional nurses in the SAMHS.

Stakeholder involvement: The guideline was developed by the first author, under the supervision of the second and third authors, and based on data from various sources: nursing students $(n=28)$, novice professional nurses $(n=13)$, unit managers $(n=9)$ and nurse educators $(n=9)$, and seven available guidelines supporting the transition of final year nursing students to professional nurses. Six $(n=6)$ experts in the academic, education or management level of the SAMHS reviewed the guideline.

Rigor of development: The entire development of the guideline was done under the supervision of experienced researchers. Triangulation of data (qualitative data and existing guidelines) was done to establish the content of the recommendations and experts were involved in review of the guideline.

Clarity and presentation of recommendations: The four themes, derived from qualitative data and available existing guidelines, formed the basis of four key recommendations and their respective sub-recommendations for nurse educators and unit managers. The level of evidence, according to LoBiondo-Wood and Haber's (2014) hierarchy of evidence, is indicated with each sub-recommendation. Levels of evidence are established as follows:

- Level I includes evidence from Best Practice Guidelines based on systematic reviews and metaanalyses;

- Level II contains evidence from randomized controlled trials and randomized cross-over studies;

- Level III includes evidence derived from controlled trials without randomization;

- Level IV includes evidence from non-experimental studies, as well as descriptive surveys, case reports, and cohort, correlation, and case control studies;

- Level V evidence is derived from systematic reviews of descriptive and qualitative studies;

- Level VI evidence is derived from single descriptive and qualitative studies; and

- Level VII evidence contains evidence derived from the opinion of experts (LoBiondo and Haber 2014, 141). 


\section{Recommendation 1: Provide support for final year nursing students and newly qualified professional nurses}

The concept "support" refers to giving strength to or encouraging or helping (Wehmeier 2005, 356). Student nurses and novice professional nurses need support and encouragement to be able to function competently and efficiently in their new roles as professional nurses. To provide support, the nurse educators are advised to:

- Pay regular visits to the students when they are allocated to the clinical area in order to support their learning (Canadian Association of Medical Radiation Technologies 2013 - Level IV, V, VI and VII evidence).

The unit managers should:

- Have an effective orientation and induction program in their various units that will clearly guide both the students and newly qualified professional nurses on the tasks and responsibilities to be undertaken in the unit (Klomp 2009- Level IV, V, VI and VII evidence).

- Ensure that peer support groups are available to give the students and newly qualified professional nurses the opportunity to obtain support from their peer mates (AONE 2010 - Level IV, V, VI and VII evidence).

- Be observant to the signs from students and newly qualified professional nurses of alienation and, if the need arises, to refer them to the relevant services e.g. psychological or social services (Klomp 2009- Level IV, V, VI and VII evidence).

- Ensure that peer forums are viable and effectively utilized to serve as the platform where students and newly qualified professional nurses are able to voice their concerns without intimidation (Study participants: Final year nursing students, Focus Group 2 - Level VI evidence).

- Give feedback on a regular basis to students and newly qualified professional nurses on their progress, as this will show that their efforts to learn are recognized (Klomp 2009 - Level IV, V, VI and VII evidence).

\section{Recommendation 2: Foster professional socialization and belonging}

Professional socialization and belonging can have a positive impact on nursing students as well as on newly qualified professional nurses by developing their personality into that of the profession and fostering the caring role of nursing as a profession. This, in turn, assists with boosting confidence and enhancing a feeling of belonging in the profession, which could further advance the retention in the profession (Caka and Lekalakala-Mokgele 2013, 3 Macintosh 2006, 954). To foster professional socialization and belonging, nurse educators are advised to:

- Establish a peer mentoring system for students allocated to different departments so as to socialize the new students in the units (Klomp 2009 - Level IV, V, VI and VII evidence). 
- Plan and implement clinical accompaniment to boost the morale of the students and give them a sense of belonging (Canadian Association of Medical Radiation Technologies 2013 - Level IV, $\mathrm{V}, \mathrm{VI}$ and VII evidence).

The unit managers are advised to:

- Allocate a mentor for each student and newly qualified professional nurse in the unit in order to socialize them into the routine of the department at a manageable pace (Klomp 2009 - Level IV, $\mathrm{V}, \mathrm{VI}$ and VII evidence)

- Include the newly qualified professional nurses in the team building sessions so as to foster the feeling of belonging (Study participants: Novice professional nurses, Focus Group 1 - Level VI evidence).

\section{Recommendation 3: Enhance a positive clinical learning environment}

Literature demonstrates that positive clinical learning environments are associated with less "reality shock" for final year nursing students as well as newly qualified professional nurses in the clinical area (Kramer, Brewer and Maguire 2013, 349).

The following suggestions are made for the nurse educators to address the issue of creating a positive clinical learning environment:

- Advocate for a Clinical Department in the hospital that will liaise with the Nursing College and will, in turn, foster continuity of learning for the students to improve their clinical skills (Study participants: Final year nursing students, nurse educators 1,2 and 6-Level VI evidence).

- Plan the student allocation program in such a way that unit rotations are done every six weeks instead of four weeks as this will afford the students the ability to settle and learn more in the unit, before being allocated or moved to a new department. A lengthier stay in the unit can boost their competency in that field (Healy and Howe 2012 - Level IV, V and VI evidence).

The suggestions for the nurse managers are to:

- Be approachable and open, so that students and newly qualified professional nurses are able to learn in a more relaxed atmosphere to enhance their clinical skills (Rush, Adamack and Gordon 2013, 8 - Level I, IV, V, VI and VII evidence).

- Advocate for newly qualified professional nurses to be provided with civilian uniforms after qualification until they have completed the necessary military courses for their promotion in the ranks. This will boost their assertiveness and sense of authority, which will develop their leadership skills and role competency (Study participants: Novice professional nurses, Focus Group 1 - Level VI evidence)

- Establish open communication channels by having regular departmental meetings where students and newly qualified professional nurses are able to communicate openly without fear (Hayes 2014 
- Level I, IV, V, VI and VII evidence).

- Evaluate the newly qualified professional nurses' clinical skills and performance on a regular basis and report to the management any prospects of the professional nurse being promoted to higher positions (Nurses Association of New Brunswick 2012 - Level VII evidence).

- Have regular in-service trainings for students and newly qualified professional nurses in order to advance in the clinical learning area and to continuously improve their competency and clinical skills (Canadian Association of Medical Radiation Technologies 2013 - Level IV, V, VI and VII evidence).

\section{Recommendation 4: Ensure retention of newly qualified professional nurses}

Organizational issues, such as staff shortages and negative attitudes of staff towards newly qualified professional nurses, impacted negatively on the transition process as well as on the retention of newly qualified professional nurse, as was raised by the participants during data collection of Phase 1. Ensuring retention of newly qualified professional nurses starts at the educational institution. The following suggestions were therefore made for the nurse educators, based on the organizational factors negatively affecting the transition and retention of newly qualified professional nurses:

- Facilitate regular meetings between the academic settings and the practice settings to ensure that continuous dialogue occurs in order to address and redress the preparation issues for the transition of final year nursing students to professional nurses (AONE 2010 - Level IV, V, VI and VII evidence).

The nurse managers should:

- Advise management on the utilization of agency nurses to curb the shortage so that the permanent staff are able to give attention to the learning needs of the students and newly qualified professional nurses (Study participants: Nurse educators 1, 2 and 5, unit manager 3 - Level VI evidence).

- Create personnel and development training programs that will promote transition and enhance retention of newly qualified professional nurses (Healy and Howe 2012 - Level IV, V and VI evidence).

- Ensure that the attitudes of staff members are positive towards the students and newly qualified professional nurses by highlighting their present and future contribution to the organization (Study participants: Final year nursing students, Focus Group 1; Unit manager 3 - Level VI evidence).

\section{DISCUSSION}

Best practice guidelines such as this guideline have the potential to improve educational outcomes as well as patient outcomes. However, the guideline's beneficial effects are contingent on its successful implementation (Registered Nurses' Association of Ontario, 2007). The guideline developed in this study is expected to enhance the facilitation of the 
transition of final year nursing students to professional nurses in the SAMHS.

The guideline should have a direct impact on the support provided, and on the socialization and belonging fostered, as well as enhancing a positive clinical learning environment for both final year nursing students and newly qualified professional nurses. The guideline should also ensure retention of newly qualified professional nurses in the workplace. Such outcomes were found in a systematic review conducted by Missen, McKenna and Beauchamp $(2014,2419)$ who state that assisting students in the transition to professional nurse reduces anxiety and stress, improves job satisfaction and retention. The guideline is also expected to enhance the awareness among nurse educators and nurse managers of the importance of a smooth transition process.

However, as the guideline has, at the time of writing, not been implemented, the implications of the guideline regarding the facilitation of the transition process, including longterm outcomes in terms of education, care and patient outcomes, remain unknown. In this respect, although existing guidelines on transition are published (Department of Health and Human Services 2015; Hayes 2014; Healy and Howe 2012; Klomp 2009; Rush, Adamack and Gordon 2013), there is a paucity of literature on studies conducted testing the feasibility of guidelines on transition. This is confirmed by Kredo, et al. $(2016,122)$ who state that guideline updating, adopting (with or without contextualization), adapting and impact evaluation are topics that are not often addressed in the literature.

A pilot study is often used in determining the feasibility of a study or guideline (Eldridge et al. 2016). It is therefore recommended that, before implementation is undertaken, the guideline should be piloted through a small-scale intervention study to test its feasibility in facilitating the transition of final year nursing students to professional nurses. A context analysis should also be done to identify what the available and required resources are in order to implement the guideline in its context. It is important to note is that recommendations were generated based on the findings of interviews with students, nurse educators and nursing managers from the SAMHS, and thus such recommendations are to be used in the military health context only. The guideline should be adapted if it is to be implemented in contexts unrelated to military health. Implementation of the guideline can be done using seminars, conferences and workshops. As Phase 1 of this study found a limited use of guidelines was found among professional nurses and nurse educators, the nurses and nurse educators should be educated on how to use the guideline, for example through a workshop or compulsory module. The guideline should be part of the orientation program of new staff members (both nurse educators and nurse managers). Furthermore, the guideline should be made accessible in various formats (e.g. hard copy and electronic copy or by using a mobile app) for the users to 
enhance its implementation and usage.

Education for professionals, including formal lecturers, workshops and in-service training and printed material were the most frequently used strategies for implementing guidelines to practice (Gagliardi and Alhabib 2015). The guideline, or parts of it, should preferably be part of the nursing education institution's and clinical institution's strategic plan, budget and timeline. Champions should be identified in both nursing education institutions and healthcare institutions to drive the implementation of the guideline. This is important as it will enhance the sustainability of the guideline's development (Registered Nurses' Association of Ontario 2007). After its implementation, this guideline and the effectiveness to facilitate transition should be evaluated using impact studies.

It is recommended that the guideline should be reviewed at least bi-annually. Review can be done by conducting an integrative literature review or systematic reviews regarding new published guidelines on transition of final year nursing students to professional nurses and interviewing experts who are not currently included in the development and review of the guideline. Finally, as existing guidelines did not include Level I, II and III evidence, it is recommended that more Level I, II and III evidence should be acquired on how to enhance student transition in a variety of healthcare contexts. This information could then be included in existing transition guidelines.

\section{CONCLUSION}

This article outlined the development and review of a guideline on the transition of final year nursing students to professional nurses in the SAMHS' context. The guideline, which is the first guideline developed for the context, provides direction to the following: provide support, foster socialization and belonging, enhance a positive clinical learning environment and ensure retention of newly qualified professional nurses. The guideline can be used by nurse educators and nursing management but requires implementation to determine its effectiveness in optimizing the transition period. Recommendations for review and implementation were made.

\section{ACKNOWLEDGEMENTS}

The authors would like to thank the participants and expert reviewers that have contributed to the development of the guideline.

\section{FUNDING STATEMENT}

This research did not receive any specific grant from funding agencies in the public, commercial, or not-for-profit sectors. 


\section{REFERENCES}

American Organization of Nurses Executives. 2010. Guiding principles: For the newly licensed nurse's transition into practice. http://www.aone.org/resources/newly-licensed-nurses-transitionpractice.pdf (Accessed 15 February 2014).

AONE see American Organization of Nurses Executives.

Brouwers, M. C. 2013. Appraisal of guidelines for research and evaluation II. http://www.agreetrust.org/wp-content/uploads/2013/10/AGREE-II-Users-Manual-and-23-itemInstrument_2009_UPDATE_2013.pdf(Accessed 12 November 2013).

Caka, E. M. 2015. Best practice guideline for the transition of final year nursing students to professional nurses in the military health service in South Africa. Port Elizabeth: Nelson Mandela Metropolitan University. $\mathrm{PhD}$ thesis in Nursing Science.

Caka, E. M. and S. Lekalakala-Mokgele. 2013. The South African Military Nursing College pupil enrolled nurses' experiences of the clinical learning environment. Health SA Gesondheid 1(18): $1-11$.

Caka, E. M., R. M. van Rooyen and P. Jordan. 2015. Dual transitions in nursing: A military perspective. Africa Journal of Nursing and Midwifery 17: S191-S208.

Canadian Association of Medical Radiation Technologies. 2013. Effective preceptorship: A guide to best practice. http:/www.camrt.ca/wp-content/uploads/2014/12/PreceptorGuidelines.pdf (Accessed 13 February 2014).

Department of Health and Human Services. 2015. Transition to practice for nurses and midwives. Guideline. Version 2. November. Hobart: Tasmanian Government. http://www.dhhs. tas.gov.au/_data/assets/pdf_file/0008/208799/TtP_Guideline_V2_20151223.pdf (Accessed 12 March 2016).

Eldridge, S. M., G. A. Lancaster, M. J. Campbell, L. Thabane, S. Hopewell, C. L. Coleman and C. M. Bond. 2016. Defining feasibility and pilot studies in preparation for randomised controlled trials: Development of a conceptual framework. PLOS ONE 11(3): e0150205. https://doi.org/10.1371/ journal.pone.0150205

Gagliardi, A. R. and S. Alhabib. 2015. Trends in guideline implementation: A scoping systematic review. Implementation Science 10(2015): 54.

Goodwin-Esola, M., M. Deely and N. Powell. 2009. Progress meetings: Facilitating role transition of the new graduate. Journal of Continuing Education in Nursing 40(9): 411-415.

Hayes, P. D. 2014. Transition to employment and professional practice guidelines: Regionally increasing baccalaureate nurses. http://ffne.org/library/library/documents/ribn-transition-toemployment-guidelines-final.pdf (Accessed 8 November 2014).

Hayman-White, K., B. Happell, R. Charleston and R. Ryan. 2007. Transition to mental health in nursing through specialist graduate programs in mental health: A review of the literature. Issues in Mental Health Nursing 28(2): 185-200.

Healy, M. and V. Howe. 2012. Study of early graduate nursing and midwifery programs. Department of Health Nursing and Midwifery Policy, Victoria Government, Melbourne. Government. http://www.health.vic.gov.au/_data/assets/pdf_file/0003/751260/EGP-Final-appendices.pdf (Accessed 7 November 2014).

Hollywood, E. 2011. The lived experiences of newly qualified children's nurses. British Journal of Nursing 20(11): 661-671.

Klomp, C. 2009. Early nurse graduate program guidelines. Building capacity and capability in the Victorian nursing workforce. Melbourne: Taylor Nelson Sofres. http://www.health.vic.gov.au/ _data/assets/pdf_file/0019/406036/EGP-all-principlesV2 .pdf(Accessed 11 October 2013).

Kramer, M., B. B. Brewer and P. Maguire. 2013. Impact of healthy work environments on new graduate nurses' environmental reality shock. Western Journal of Nursing Research 35(3): 348-383. 
Kredo, T., S. Bernhardsson, S. Machingaidze, T. Young, Q. Louw, E. Ochodo and K. Grimmer. 2016. Guide to clinical practice guidelines: The current state of play. International Journal for Quality in Health Care 28(1): 122-128.

LoBiondo-Wood, G. and J. Haber. 2014. Nursing research: Methods and critical appraisal for evidence-based practice. $8^{\text {th }}$ Edition. St Louis, Missouri: Mosby.

Macintosh, C. 2006. Caring: The socialisation of pre-registration student nurses: A longitudinal qualitative descriptive study. International Journal of Nursing Studies 43(8): 953-962.

Mannix, J., L. Wilkes and L. Luck. 2009. Key stakeholders in clinical learning and teaching in Baccalaureate Nursing Programs: A discussion paper. Contemporary Nursing 32(1-2): 59-68.

Missen, K., L. McKenna and A. Beauchamp. 2014. Satisfaction of newly graduated nurses enrolled in transition-to-practice programmes in their first year of employment: A systematic review. Journal of Advanced Nursing 70(11): 2419-2433.

Mooney, M. 2007. Newly qualified Irish nurses' interpretation of their preparation and experiences of registration. Journal of Clinical Nursing 16(9): 1610-1617.

Nurses Association of New Brunswick. 2012. Practice guideline: Graduate nurse scope of practice. http://www.nanb.nb.ca/media/resource/NANB-PracticeGuideline-GraduateNurseScopeOf Practice-E.pdf (Accessed 11 October 2014).

Registered Nurses' Association of Ontario. 2007. Sustainability of best practice guideline implementation. http://rnao.ca/sites/rnao-ca/files/sustainability_march_07.pdf. (Accessed 27 June 2018).

Rush, K., M. Adamack and J. Gordon. 2013. Expanding the evidence for new graduate nurse transition best practices. Michael Smith Foundation for Health Research. Final Report. http://www.msfhr.org/sites/default/files/Expanding_the_Evidence_for_New_Graduate_Nurse_T ransition_Best_Practices.pdf. (Accessed 13 November 2014).

Spoelstra, S. and L. B. Robbins. 2010. A qualitative study of role transition from RN to APN. International Journal of Nursing Education Scholarship 7(20): 1-16.

Van Rooyen, D. (R. M.), P. Jordan, W. ten Ham-Baloyi and E. M. Caka. 2018. A comprehensive literature review of guidelines facilitating transition of newly graduated nurses to professional nurses. Nurse Education in Practice 30(2018): 35-41.

Wehmeier, S. 2005. Oxford advanced leaner's dictionary. $7^{\text {th }}$ Edition. Oxford: Oxford University Press.

Wielandt, D. M., G. M. Altmiller, M. T. Dorr and Z. R. Wolf. 2007. Clinical transition of Baccalaureate nursing students during preceptored pre-graduation practicums. Nursing Education Perspectives 28(6): 315-321. 